\title{
ANALISIS DAN PERANCANGAN SISTEM INFORMASI PENENTUAN SHUTDOWN POINT PADA PT. LARIS SUMUT MAKMUR MEDAN
}

\author{
Erikson Damanik \\ Komputerisasi Akuntansi, Politeknik Bisnis indonesia \\ email: damanik.1969@gmail.com
}

\begin{abstract}
Determining the shutdown point is a financial analysis that can help companies observe the continuity of the company's business, so that it can be seen whether the company can still be continued or terminated. Determination of the shutdown point can also help the company in knowing the sales volume that the company must achieve so that there is no loss. PT. Laris Sumut Makmur Medan is a company engaged in the sale of industrial engine oil. In its operations, companies often experience losses, which are caused by increasingly fierce business competition and increased operating costs. Therefore, the operational manager is expected to be able to examine the continuity of the company's business in order to observe the problems that occur and as a reference for decision making, so that it can be seen whether the company's business can be continued or stopped. However, this is difficult for the operational manager to do because there is no support for an information system for determining the shutdown point in the company. To solve this problem, an information system for determining the shutdown point in the company is designed. The design of the information system for determining the shutdown point can be a basis for system developers to continue it. to the stage of system construction (making program code) to make it easier for companies to make policies regarding the continuity of their business.
\end{abstract}

Keywords : Shutdown point, industrial, Engine, Oil.

\section{PENDAHULUAN}

Kemajuan teknologi yang demikian pesat mendorong setiap orang untuk memanfaatkan hasil dari kemajuan teknologi tersebut dengan sebaik-baiknya [1]-[6], begitu juga halnya dengan kemajuan teknologi komputer, dimana teknologi komputer mempunyai peranan yang penting untuk membantu perusahaan dalam memecahkan berbagai masalah yang dihadapi dan penyajian informasi yang cepat [7]-[17], [18]-[25].

Salah satu pemanfaatan teknologi komputer adalah dalam penentuan shutdown point. Penentuan shutdown point merupakan suatu analisis keuangan yang dapat membantu perusahaan dalam mengamati kontinuitas usaha perusahaan, sehingga dapat diketahui apakah perusahaan masih bisa diteruskan maupun dihentikan. Penentuan shutdown point juga dapat membantu perusahaan dalam mengetahui volume penjualan yang harus dicapai oleh perusahaan agar tidak terjadi kerugian [26], [27]. Dalam penentuan shutdown point, seluruh biaya perusahaan yang tidak dibayar secara tunai harus dikeluarkan, seperti biaya penyusutan aktiva tetap. Dalam proses penentuan shutdown point menggunakan analisis impas, di mana merupakan analisis yang dapat membantu perusahaan dalam mengetahui volume penjualan minimal yang dapat menutupi pengeluaran biaya operasional.

PT. Laris Sumut Makmur Medan merupakan perusahaan yang bergerak di bidang penjualan oli mesin industri, seperti 677, 699, 688, Centra 0, dan lainnya. Dalam operasionalnya, perusahaan sering mengalami kerugian, yang disebabkan oleh persaingan bisnis yang semakin ketat dan meningkatnya biaya operasional. Oleh karena itu, manajer operasional diharapkan dapat meneliti kontinuitas usaha perusahaan dengan tujuan untuk mengamati masalah yang terjadi dan sebagai acuan pengambilan keputusan, sehingga dapat diketahui apakah usaha perusahaan dapat diteruskan maupun dihentikan.

Akan tetapi, hal tersebut sulit dilakukan manajer operasional karena belum adanya 
dukungan sistem informasi penentuan shutdown point pada perusahaan. Manajer operasional masih sulit mengetahui volume penjualan yang harus dicapai oleh perusahaan agar tidak terjadi kerugian. Selain itu, manajer operasional juga masih sulit mengetahui strategi pemasaran yang tepat untuk menghindari terjadinya kerugian.

Untuk mengatasi hal tersebut di atas, dilakukan perancangan Sistem Informasi Penentuan Shutdown point pada PT. Laris Sumut Makmur Medan untuk mempermudah perusahaan mengambil kebijakan mengenai kontinuitas usaha yang dijalankan. Rancangan input dan output meliputi pencatatan data barang, data customer, data perkiraan biaya, data penjualan, dan data biaya operasional (biaya tetap dan biaya variabel) serta laporan penjualan, faktur penjualan, laporan biaya tetap, laporan biaya variabel, laporan biaya tidak tunai, laporan penentuan shutdown point.

Dengan adanya sistem informasi penentuan shutdown point ini, maka manajer operasional dapat dengan mudah mengetahui apakah perusahaan masih bisa diteruskan maupun dihentikan. Manajer operasional dapat mengetahui volume penjualan yang harus dicapai oleh perusahaan agar tidak terjadi kerugian dan strategi pemasaran yang perlu diterapkan. Informasi shutdown point pada perusahaan menjadi acuan bagi manajer operasional dalam pengambilan keputusan mengenai kontinuitas usaha perusahaan.

\section{METODE PENELITIAN}

\section{Metodologi Pengembangan Sistem}

Dalam analisis dan perancangan sistem informasi penentuan shutdown point, penulis menggunakan metode SHPS dengan langkahlangkah pengembangan sistem pada perusahaan dengan tahapan:

1. Mengidentifikasikan masalah, peluang dan tujuan

Penulis akan meneliti masalah yang dihadapi perusahaan, menemukan peluang perusahaan, dan melihat beberapa aspek dalam aplikasi-aplikasi sistem informasi yang diusulkan untuk membantu perusahaan mencapai tujuan-tujuan yang diinginkan.

2. Menentukan syarat-syarat informasi
Penulis akan menginput syarat-syarat untuk para pemakai sistem, menentukan data yang diperlukan, melakukan wawancara, mengamati perilaku pembuat keputusan, dan prototyping untuk menggambarkan proses sistem berjalan perusahaan dengan bagan alir dokumen, di mana proses sistem berjalan pada perusahaan meliputi pengolahan data penjualan, biaya operasional dan pembuatan laporan.

3. Menganalisis kebutuhan sistem

Penulis akan menggunakan diagram alir data (DFD) untuk menyusun daftar input, proses dan output fungsi bisnis untuk menganalisis kebutuhan sistem usulan. Dari diagram alir data ini, akan dikembangkan suatu kamus data yang berisikan daftar seluruh item data yang digunakan dalam sistem usulan berikut juga spesifikasinya.

4. Merancang sistem yang direkomendasikan Berdasarkan DFD logis sistem usulan, penulis akan membuat rancangan basis data yang meliputi normalisasi, struktur tabel database, dan relasi antar tabel, dan rancangan user interface yang meliputi rancangan masukan, rancangan keluaran, dan rancangan menu.

\section{Teknik Pengumpulan Data}

Teknik pengumpulan data yang digunakan yaitu: Sampling dan Investigasi, dilakukan dengan mengambil contoh dokumen perusahaan untuk dianalisis kelemahan dan keunggulannya, seperti formulir data barang, formulir data penjualan, formulir data biaya operasional, faktur penjualan, laporan penjualan, dan laporan biaya operasional. Selain itu, juga dilakukan wawancara terhadap staf penjualan untuk mengetahui informasi penjualan barang dan staf akuntansi untuk mengetahui informasi biaya operasional pada perusahaan, dan melakukan observasi secara langsung terhadap prosedur kerja staf penjualan dalam bertransaksi dengan customer dan staf akuntansi dalam mencatat data biaya operasional.

\section{HASIL DAN PEMBAHASAN}

Hasil perancangan masukan pada sistem informasi penentuan shutdown point terdiri dari: 


\section{Form Data Barang}

Form ini berfungsi untuk memasukkan data-data barang. Form input ini seperti pada Gambar 1 .

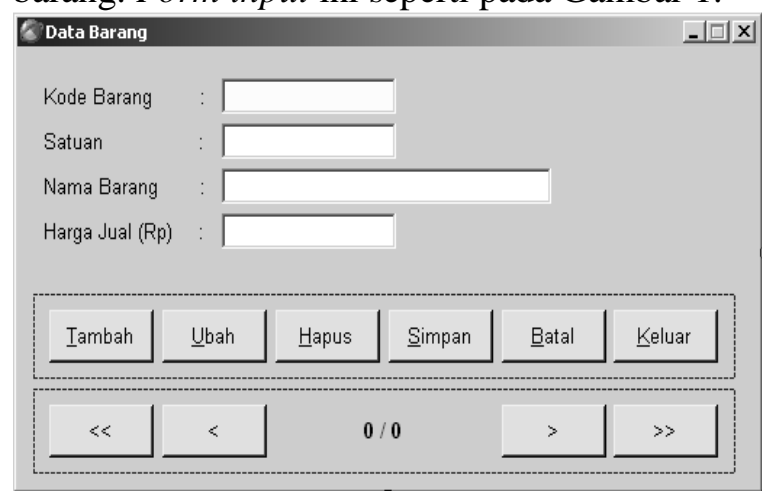

Gambar 1. Form Data Barang

\section{Form Data Customer}

Form ini berfungsi untuk memasukkan data-data customer. Form data customer ini seperti pada Gambar 2.

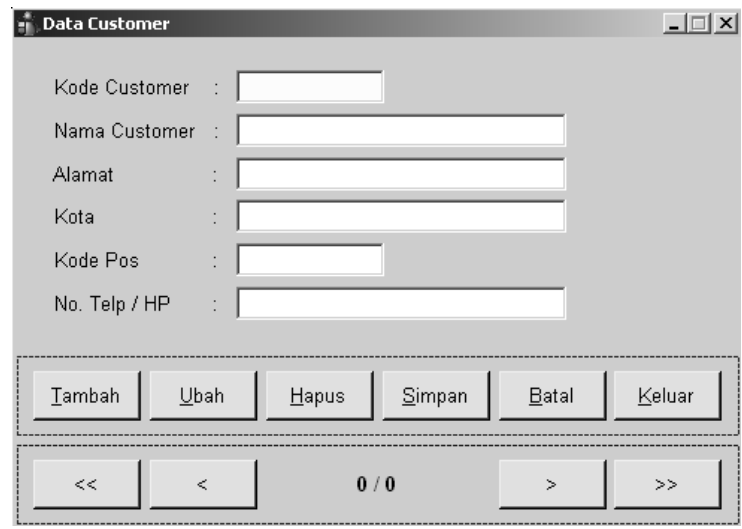

Gambar 2. Form Data Customer

Form Data Perkiraan Biaya

Form ini untuk memperkirakan biaya, bentuk form ini seperti pada Gambar 3.

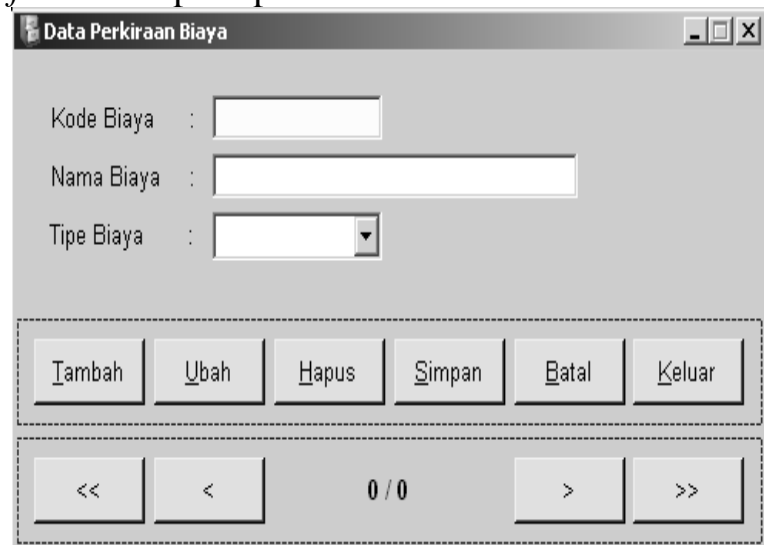

Gambar 3. Form Data Perkiraan Biaya
Form Data Penjualan

Form ini berfungsi untuk memasukkan data penjualan. Form ini seperti pada Gambar 4.

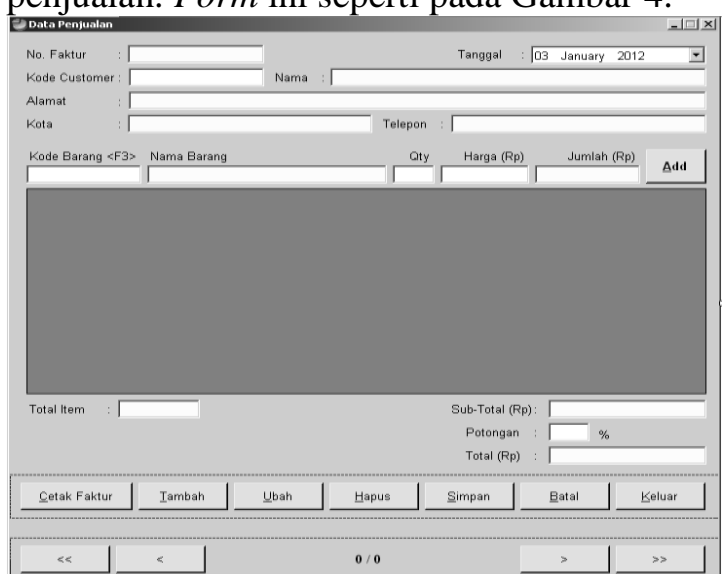

Gambar 4. Form Data Penjualan

Form Data Biaya Operasional

Bentuk rancangan form input ini seperti pada Gambar 5.

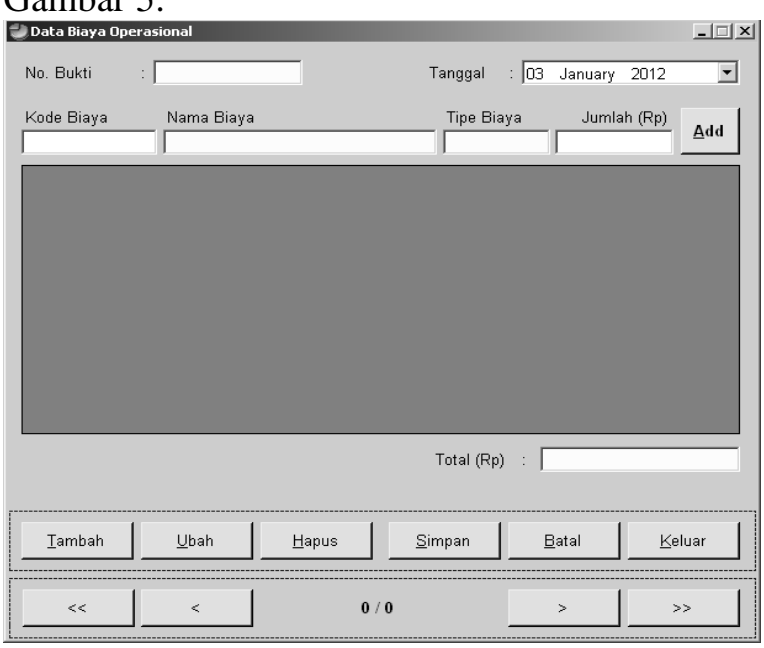

Gambar 5. Form Data Biaya Operasional

\section{Form Penentuan Shutdown Point}

Bentuk rancangan form proses ini seperti pada Gambar 6.

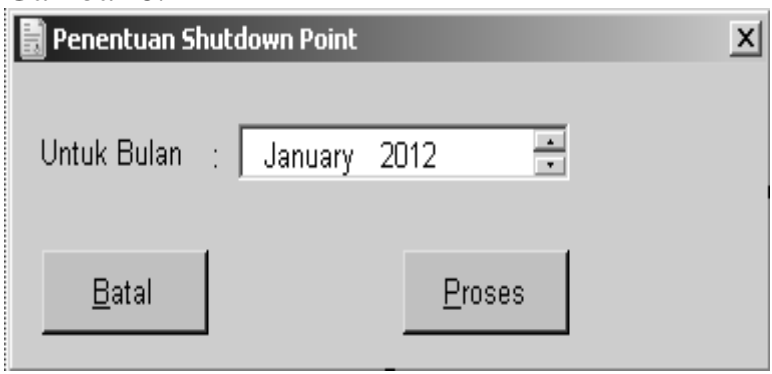

Gambar 6. Form Penentuan Shutdown Point 
Laporan Penentuan Shutdown Point

Bentuk rancangan laporan ini seperti pada Gambar 7.

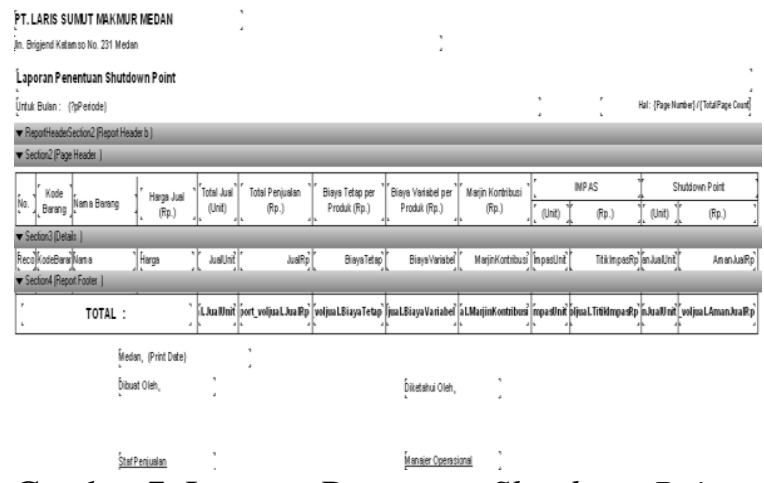

Gambar 7. Laporan Penentuan Shutdown Point

\section{KESIMPULAN \\ Kesimpulan}

Dari hasil penelitian sistem informasi penentuan shutdown point pada PT. Laris Sumut Makmur Medan, dapat diambil bebrapa kesimpulan antara lain:

1. Dengan adanya rancangan sistem informaasi ini, perusahaan memperoleh suatu logika proses yang berisi penanganan pengolahan data penjualan, biaya operasional, dan penentuan shutdown point.

2. Dengan adanya rancangan sistem informasi ini, memudahkan perusahaan mengembangkannya menjadi bentuk aplikasi komputer, sehingga perusahaan dapat mengambil kebijakan mengenai kontinuitas usaha yang dijalankan.

\section{REFERENSI}

[1] P. Adi, D. Prasetya, A. Setiawan, N. Nachrowie, and R. Arifuddin, "Design Of Tsunami Detector Based Sort Message Service Using Arduino and SIM900A to GSM/GPRS Module," Proc. Proc. 2nd Int. Conf. Adv. Sci. Innov. ICASI 2019, 18 July, Banda Aceh, Indones., 2019.

[2] P. D. P. Adi and A. Kitagawa, "ZigBee Radio Frequency (RF) performance on Raspberry Pi 3 for Internet of Things (IoT) based blood pressure sensors monitoring," Int. J. Adv. Comput. Sci. Appl., 2019.
[3] M. Niswar et al., "Performance evaluation of ZigBee-based wireless sensor network for monitoring patients' pulse status," in Proceedings - 2013 International Conference on Information Technology and Electrical Engineering: "Intelligent and Green Technologies for Sustainable Development", ICITEE 2013, 2013.

[4] P. D. P. Adi and A. Kitagawa, "Performance evaluation of E32 long range radio frequency $915 \mathrm{MHz}$ based on internet of things and micro sensors data," Int. J. Adv. Comput. Sci. Appl., vol. 10, no. 11, pp. 38-49, 2019.

[5] P. Dani Prasetyo Adi and A. Kitagawa, "A performance of radio frequency and signal strength of LoRa with BME280 sensor," TELKOMNIKA (Telecommunication Comput. Electron. Control., vol. 18, no. 2, p. 649, Apr. 2020.

[6] P. D. P. Adi and A. Kitagawa, "Quality of Service and power consumption optimization on the IEEE 802.15.4 pulse sensor node based on Internet of Things," Int. J. Adv. Comput. Sci. Appl., 2019.

[7] V. M. M. Siregar, "Sistem Pendukung Keputusan Penentuan Insentif Bulanan Pegawai Dengan Menggunakan Metode Naïve Bayes," SISTEMASI, vol. 7, no. 2, pp. 87-94, 2018.

[8] V. M. M. Siregar, "Sistem Informasi Pembelian Dan Penjualan Pakaian Pada Galoenk Distro Pematangsiantar," JurTI (Jurnal Teknol. Informasi), vol. 1, no. 2, pp. 219-227, 2017.

[9] H. A. Simbolon and V. M. M. Siregar, "Perancangan Sistem Informasi Berbasis E-Commerce Untuk Peningkatan Penjualan Produk Jersey Olah Raga," $J$. Tek. Inf. dan Komput., vol. 1, no. 2, pp. 49-54, 2018.

[10] V. M. Siregar, H. Sugara, and G. A. Purba, "APLIKASI PENCATATAN LAPORAN PENJUALAN KITA-KITA. NET BERBASIS WEB," J. Tek. Inf. dan Komput., vol. 2, no. 1, pp. 80-86, 2019.

[11] V. M. M. Siregar, "Perancangan Website Sebagai Media Promosi Dan Penjualan Produk," TAM (Technology Accept. Model., vol. 9, no. 1, pp. 15-21, 2018.

[12] V. M. Siregar and H. Sugara, 
"Perancangan Dan Implementasi Aplikasi Penggajian Berbasis Dekstop Pada Murni Sadar English Course," J. Tek. Inf. dan Komput., vol. 1, no. 2, pp. 42-48, 2018.

[13] V. M. M. Siregar, "Sistem Informasi Pendataan Logistik Aktiva Tetap PT. Bank Central Asia, Tbk Kantor Cabang Pematangsiantar," SISTEMASI, vol. 7, no. September, pp. 250-258, 2018.

[14] V. M. Mulia Siregar and H. Sugara, "Implementation of artificial neural network to assesment the lecturer's performance," IOP Conf. Ser. Mater. Sci. Eng., vol. 420, no. 1, p. 012112, Oct. 2018.

[15] S. P. Tamba, M. D. Batubara, W. Purba, M. Sihombing, V. M. Mulia Siregar, and J. Banjarnahor, "Book data grouping in libraries using the k-means clustering method," J. Phys. Conf. Ser., vol. 1230, no. 1, p. 012074, Jul. 2019.

[16] V. M. M. Siregar, "Perancangan Sistem Informasi Inventaris Barang Pada Sekolah SMA Negeri 4 Pematangsiantar," IT $J$. Res. Dev., vol. 3, no. 1, pp. 54-61, 2018.

[17] V. M. M. Siregar, H. Sugara, and I. M. Siregar, "Perancangan Sistem Informasi Pendataan Barang Pada PT. Serdang Hulu," J. Comput. Bisnis, vol. 12, no. 2, pp. 111-117, 2018.

[18] G. J. Yanris, “Analisis Dan Implementasi Data Mining Dalam Menganalisa Kendala Akademik Yang Sering Dikeluhkan Mahasiswa AMIK Labuhanbatu (Studi Kasus : Amik Labuhanbatu)," Informatika, vol. 4, no. 1, pp. 15-24, 2016.

[19] V. Sihombing and G. J. Yanris, "PENERAPAN APLIKASI DALAM MENGOLAH ASET DESA (STUDI KASUS: KEPENGHULUAN SRI KAYANGAN)," J. Mantik Penusa, vol. 4, no. 1, pp. 12-15, 2020.

[20] W. Purba, S. Aisyah, and S. P. Tamba, "Perancangan Sistem Pakar Diagnosa Penyakit Mata Katarak Menggunakan Konsep Metode Runut Mundur," JUSIKOM PRIMA (Junal Sist. Inf. Ilmu Komput. Prima), vol. 1, no. 1, 2017.

[21] Fricles Ariwisanto Sianturi, "Analisa metode teorema bayes dalam mendiagnosa keguguran pada ibu hamil berdasarkan jenis makanan," Tek. Inf. dan Komput., vol. 2, no. 1, pp. 87-92, 2019.

[22] J. Simatupang and S. Sianturi, "PERANCANGAN SISTEM INFORMASI PEMESANAN TIKET BUS PADA PO. HANDOYO BERBASIS ONLINE," J. Intra Tech, vol. 3, no. 2, pp. 11-25, 2019.

[23] V. Sihombing, "Aplikasi Simade (Sistem Informasi Manajemen Desa) Dalam Meningkatkan Pelayanan Administrasi di Kepenghuluan Bakti Makmur Kecamatan Bagan Sinembah Kab. Rokan Hilir Riau," SISTEMASI, vol. 7, no. September, pp. 292-297, 2018.

[24] V. Sihombing, "Sistem Informasi Penjualan Mobil Suzuki Di Dealer Bagan Batu," SISTEMASI, vol. 7, no. 2, pp. 113119, 2018.

[25] J. Simatupang, "Perancangan Sistem Inventori Barang pada Toko Nichos Jaya Menggunakan Metode FIFO," J. Intra Tech, vol. 1, no. 1, pp. 31-42, 2017.

[26] T. Arletta, "Pra-Rancangan Pabrik Diklorometana dari Metil Klorida dan Klorin Dengan Kapasitas 8.500 Ton/Tahun," J. Tek. Kim. Univ. Tanjungpura, vol. I, no. 1, pp. 1-6, 2019.

[27] N. Y. Cahyadi and Sulistiyo, "Analisis Biaya Volume Laba Sebagai Alat Perencanaan Laba Pada CV Waringin Putih Semarang," J. Akunt. Keuang. BISNIS Terap., vol. 1, no. 1, pp. 10-28, 2018. 